\title{
The rise and fall of infectious diseases: Australian perspectives, 1914-2014
}

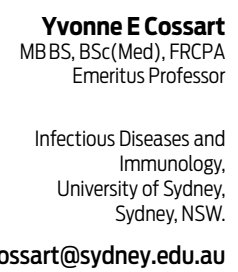

doi: 10.5694/mjal4.00112 n 1914, when the British Medical Association launched the Medical Journal of Australia, the medical profession and the general public believed that infectious diseases would soon be conquered. Acrimonious 19th century disputes between the contagionists and the sanitarians ${ }^{1}$ had given way to an alliance which was steadily improving health. Rising living standards reduced infant deaths from gastroenteritis, through better food and water hygiene, and reduced deaths from "consumption" (tuberculosis), because of better nutrition. ${ }^{2}$ The success of rat extermination in controlling plague in Sydney ${ }^{3}$ provided a triumphant validation of new microbiological theories; Joseph Lister's carbolic spray was adopted by local surgeons; ${ }^{4}$ Emil von Behring's antitoxin treatment reduced mortality from diphtheria, ${ }^{5}$ and Paul Ehrlich's vision of a magic bullet to cure all infections was given credibility by the efficacy of Salvarsan (arsphenamine, an arsenic-containing compound) against syphilis. ${ }^{6}$ Maritime quarantine provided a significant, if not impregnable, barrier to the introduction of epidemic diseases. ${ }^{7}$ The $M J A$ reflected the progressive mentality of Australian doctors through reports on new international discoveries and leading articles.

\section{The challenges of tuberculosis and syphilis}

In reality though, infection still caused at least a quarter of all deaths, ${ }^{8} 10 \%$ due to tuberculosis alone. Many of the victims were children or young adults. Eradication of bovine tuberculosis produced a welcome fall in infant cases, but about 4000 cases continued to be notified annually between 1917 and 1950. The fine sanatorium buildings in "healthy" locations such as the Blue Mountains are reminders of the desperate attempts to combine sanitary and microbiological principles by isolating patients to prevent spread of the disease while they were treated with rest and diet.9,10 During World War II (WWII), intensive screening of Australian troops by miniature $x$-ray was followed up with bacteriological testing to identify patients with active infection, for whom treatment was compulsory. The success of this program prompted a postwar attempt to eradicate the disease from the civilian population, and the advent of streptomycin and sickness benefit payments made compulsory treatment acceptable to the community. ${ }^{11}$

Tuberculosis has again become resurgent in many countries. The high expense and long duration of triple therapy test the resources of the poorest countries. Undertreatment allows emergence of multidrug-resistant strains for which treatment reverts to pre-antibiotic options. In Australia, such strains are, mercifully, still uncommon.

Syphilis also imposed a high burden of chronic disease on society. In 1914, about $5 \%$ of admissions to mental institutions and $60 \%$ of cases of aortic aneurysm in Victoria were due to tertiary syphilis, while $10 \%$ of pregnant women had positive Wassermann test results. ${ }^{12}$ The social stigma of sexually transmitted diseases and the heroic nature of combined mercurial and Salvarsan therapy deterred many

\begin{abstract}
Summary
Australia has been fortunate in its experience with infectious diseases over the past century. By the 1960s, many communicable diseases were controlled through a combination of high living standards, progressive adoption of vaccines and antimicrobial treatment.

- Australian medical scientists have made substantial contributions to the understanding of many historically significant communicable diseases and global initiatives for control.

- New challenges have emerged as previously unrecognised viral infections have emerged, and microbial resistance to antibiotics has developed in many old pathogens.

- Ongoing evolutionary forces, both environmental and social, change the balance between humans and microbes. The effects of these forces are most sorely felt in poor countries and communities.
\end{abstract}

asymptomatic patients from seeking treatment. Notification of acute cases and compulsory treatment were not successfully implemented, even in the army. In civilian settings, policies of testing only female prostitutes doomed any hope of eradication. ${ }^{6}$

\section{Vaccination against endemic diseases}

Many acute infections also remained endemic. There were dedicated wards for patients with typhoid in general hospitals, and the prevalence and mortality of typhoid remained high until the advent of antibiotics. Bedside vigils to await the crisis of pneumonia were all too familiar, and childhood infections claimed many young lives. In 1911, gastroenteritis, diphtheria, scarlet fever, whooping cough and measles between them killed one of every 30 live-born children. ${ }^{13}$ About as many more died from pneumonia and meningitis. In the interwar decades, diphtheria and pertussis vaccines were produced in the newly established Commonwealth Serum Laboratories and school-based vaccination began. But in 1928, public confidence was shaken by the Bundaberg tragedy, in which a multidose vial of diphtheria toxin-antitoxin became contaminated with staphylococci from the skin of a vaccinee. Twelve other children died. ${ }^{14}$ This galvanised regulation of vaccine manufacture, safety testing and surveillance for adverse effects. However, almost a century on, the antivaccination movement still opposes mass vaccination of children in early life.

\section{World War I and its aftermath}

During its first few years of publication, the $M J A$ reported on mortality due to infection among WWI troops, which exceeded combat deaths. ${ }^{15}$ But the battlefields were also a clinical laboratory where the efficacy of tetanus antitoxin was proven and typhoid vaccination was introduced. 


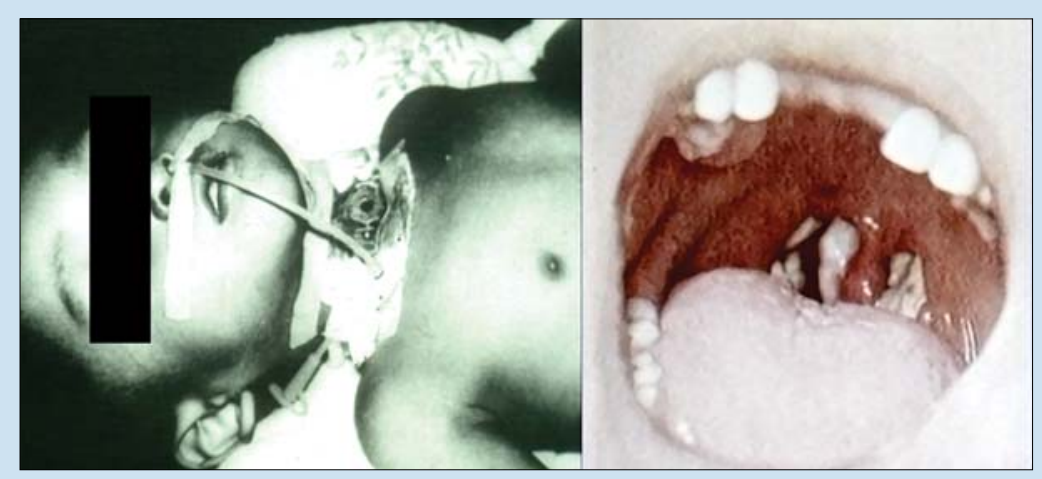

Diptheria*

The MJA also reported episodes which, with hindsight, showed that evolutionary forces were altering the balance between microbes and their human hosts. In 1918, influenza killed more Europeans than had perished in the war. The source of the pandemic strain remains obscure, but there is no doubt about the role of returning troops in its global spread. Australia's isolation and its quarantine system protected it for some time, but eventually the country experienced a catastrophic outbreak. ${ }^{12}$ Australia became an active participant in the subsequent international efforts to maintain surveillance and produce effective influenza vaccines. Pivotal influenza studies led by Frank Macfarlane Burnet at the Walter and Eliza Hall Institute were conducted during this period, and the Institute's interests soon broadened into basic scientific research on many important infections. In the postwar period, the establishment of the Australian National University strengthened the national capability in infectious diseases research.

Poliomyelitis was on the increase in the most "hygienic" countries of Scandinavia, North America and Australasia: a paradox for an infection spread by the faecal-oral route. This was the penalty for the delay in the average age when infection occurred, which was a consequence of improved hygiene. This in turn increased the numbers of clinical cases because the chance of neurological involvement increased spectacularly with age. ${ }^{16}$ The crippling legacy of infection made the sight of children with leg braces all too familiar in schools nationwide, while the invention of the iron lung enabled many patients with respiratory paralysis to survive.

\section{Vaccine-preventable diseases}

Norman Gregg's pivotal 1941 discovery of the role of rubella in causing congenital defects ${ }^{17}$ altered scientific attitudes to infections during pregnancy. It was almost two decades before cell culture techniques paved the way for vaccines against polio, and then other childhood infections. The growing list of vaccines demanded new combinations to reduce the number of injections needed, and the cost became an issue even in wealthy countries where the plummeting prevalence of vaccine-preventable diseases justified the investment. ${ }^{18}$ In the second half of the 20th century, even the basic triple antigen (diphtheria, tetanus, pertussis) was unaffordable in many developing countries, but international philanthropy plus political support have progressively been mobilised, resulting in significant reduction of vaccine-preventable disease. Money is not the only problem. The projected global eradication of polio has stalled because conflicts in Africa and Pakistan have disrupted infrastructure and fanned ideological doubts about the political motivations of governments and charities. ${ }^{19}$

In the optimistic political climate of the post-WWII years, the World Health Organization undertook an unprecedented program to achieve global eradication of smallpox. Frank Fenner was chairman of the project's management commission. Using Edward Jenner's 18th century vaccination technique and an international army of field workers, smallpox eradication was achieved in $1980 .{ }^{20}$ It remains the only example of intentional eradication of a human infectious disease.

Not all microbial evolution resulted in populations of organisms with increased virulence for humans. Scarlet fever, after causing devastating epidemics in the late 19th century, declined in terms of incidence and mortality by the 1950s. This was attributed to the loss of toxin-encoding genes from Streptococcus pyogenes. Conversely, recent resurgence of severe streptococcal infections underlines the mutability of "old" pathogens. ${ }^{21}$

\section{Antimicrobial drugs}

Patients

expected to recover from septicaemia, pneumonia and even meningitis; but it did not take long for the first drug-resistant organisms to appear
Sulfonamides made their spectacular entry into medicine just before WWII and cut the mortality from pneumonia and puerperal fever dramatically. Prontosil, a forerunner of all sulfonamide drugs, was not patentable, and manufacturers flooded the market with sulfonamide-like drugs. Penicillin soon followed - with Australian scientist Howard Florey being a key figure in its development — and was quickly adopted in military medicine. The antibiotic era had begun; as discovery followed discovery, it seemed that no bacterial infection would remain untreatable. Osteomyelitis, empyema, rheumatic fever and subacute bacterial endocarditis disappeared from the wards, and gonorrhoea and syphilis notifications plummeted. Patients expected to recover from septicaemia, pneumonia and even meningitis; but it did not take long for the first drug-resistant organisms to appear.

Sophisticated medical technology has offered unprecedented opportunities to microorganisms. Drug resistance has rapidly developed owing to selective pressure resulting from profligate use of antibiotics in medicine and agriculture. Australian hospitals experienced some of the earliest outbreaks of antibiotic-resistant staphylococci, ${ }^{22}$ which led to radical improvements in infection control. Although most of the resistant organisms were no more (and often less) virulent than the original susceptible strains, their competitive advantage meant that acute urinary infections could no longer be reliably treated with ampicillin, nor gonorrhoea with penicillin, by the mid 1980s. Discovery of new antibiotics could not keep pace, and regulatory attempts to restrict their use have proved difficult. ${ }^{23}$

\section{Emerging infections}

Transfusion-associated hepatitis B infection was discovered during WWII. ${ }^{24}$ After the virus was identified in 1968, it was found that about $0.1 \%$ of most Western populations were chronically infected, but carrier rates of $10 \%$ or more were common in Asia and Africa. ${ }^{25}$ Moreover, these rates 
were maintained by silent transmission - from mother to infant during delivery, rather than by intravenous drug use or blood transfusion. ${ }^{26}$ Before blood banks started screening donated blood for hepatitis B, transfusion was a major route of transmission of acute hepatitis B infection in Western countries. The need for mass screening prompted development of commercial testing kits, which have revolutionised laboratory diagnostic services.

The most concerning feature of hepatitis B infection was the recognition during the 1970s that adult carriers often developed liver cancer, which was then the leading cause of cancer deaths in Asia. ${ }^{27}$ Rather than a rarity, hepatitis B was a major global health problem; this justified universal infant vaccination, which was made possible by recombinant DNA technology in the 1980s. The hepatitis B vaccine was the first human recombinant DNA vaccine and the first human cancer vaccine.

Other agents soon emerged from obscurity, often in response to changes in human activity. AIDS first appeared in the gay communities of "world cities" in the early 1980s - the downside of sexual liberation. The inexorable rise in prevalence and apparently inevitable mortality of HIV infection spurred public health initiatives and scientific investigation. In Australia, safe-sex campaigns had an almost immediate effect in reducing numbers of new cases, as did controversial needle-exchange and harm-minimisation strategies for injecting drug users. ${ }^{28}$ Global investment in research led to effective antiviral drugs and greatly extended the healthy lifespan of infected individuals in Western countries. However, in the populous countries of Africa, South America and Asia, heterosexual transmission dominated and led to epidemics of neonatal infection via transplacental transmission. ${ }^{29}$ This social and economic catastrophe reawakened respect for infection, and also fuelled fear of nosocomial transmission of bloodborne viruses.

The shadowy entity of non-A, non-B hepatitis unexpectedly proved to cause both liver cirrhosis and cancer. Acute hepatitis $\mathrm{C}$ infection causes only minor symptoms, but the hepatitis $C$ virus often establishes chronic infection with sinister consequences. Tests were developed to screen donated blood and it soon became apparent that injecting drug use had silently amplified prevalence of hepatitis $\mathrm{C}$ infection in young people in Western countries. ${ }^{30}$ Hepatitis C infection became the commonest indication for liver transplant in Australia, ${ }^{31}$ and health authorities struggled to find an effective control strategy. Treatment was protracted and beset by the adverse effects of interferon, a key component of drug regimens that were initially used. Newer drugs achieve high cure rates, but cost puts them out of reach for patients in poor countries, where the reservoir of infection remains high.

Human papillomavirus was the fourth "new" infection to engage late 20th century society. Genital warts were well known to the ancient Romans, and for centuries they were regarded as an embarrassing but harmless sexually transmissible disease. This attitude changed dramatically when their association with cervical cancer was established in the 1980s. ${ }^{32}$ The high-risk types of papillomavirus produce "flat" penile warts which are easily ignored, but results of cervical cytology testing made the cancer connection - it was noted that cells with telltale warty changes were often seen in cervical smears which had malignant or premalignant changes. In Australia, preventive human papillomavirus vaccination was pioneered by Ian Frazer and viral DNA detection has been added to screening by Pap smear, but neither of these approaches are affordable in poor countries, where death rates from cervical cancer are highest. ${ }^{33}$

\section{The challenges of demographic and environmental change}

In 2014, old infections still lurk, while human and environmental changes create new opportunities. Malaria — which depends on humans as a reservoir for the parasite and mosquitoes for transmission - was vulnerable to a combination of treating patients with drugs and spraying the environment with dichlorodiphenyltrichloroethane (DDT) to kill mosquitoes. Large areas of the temperate zone and even the tropics became malaria free but, because mosquito eradication measures were inconsistently applied, drug-resistant parasites and DDT-resistant mosquitoes soon emerged. In the absence of an effective vaccine, prevention now relies on avoidance of mosquito bites by use of repellents, protective clothing and screens, plus an ever-diminishing number of effective prophylactic drugs. Malaria has been holding its own in many countries, aided by global warming. ${ }^{34}$

Military deployment of troops in exotic areas and largescale movement of refugees are associated with outbreaks of communicable diseases. Cholera has been a recurrent problem when people seek shelter from war or natural disaster, most recently in Haiti. ${ }^{35}$

Hantaan virus ${ }^{36}$ caused over 3000 cases of Korean haemorrhagic fever and almost 300 deaths among American troops during the Korean war. The soldiers were exposed through inhalation of aerosolised rodent faeces when camped in wilderness areas. Other haemorrhagic fevers - such as Ebola virus disease and Lassa fever, for which native wildlife act as reservoirs - have caused human outbreaks with high mortality, particularly in sub-Saharan Africa. Australia has several indigenous arboviruses, including Murray Valley encephalitis, and Ross River and Barmah Forest viruses. As global population pressure drives clearance of forested areas for agriculture, humans have become targets for many infections carried by wild animals. In Australia, outbreaks of Hendra virus infection and the emergence of the Australian lyssavirus have been linked to contact with flying foxes. ${ }^{37}$

Severe acute respiratory syndrome (SARS), which caused a deadly outbreak of respiratory disease centred in southern

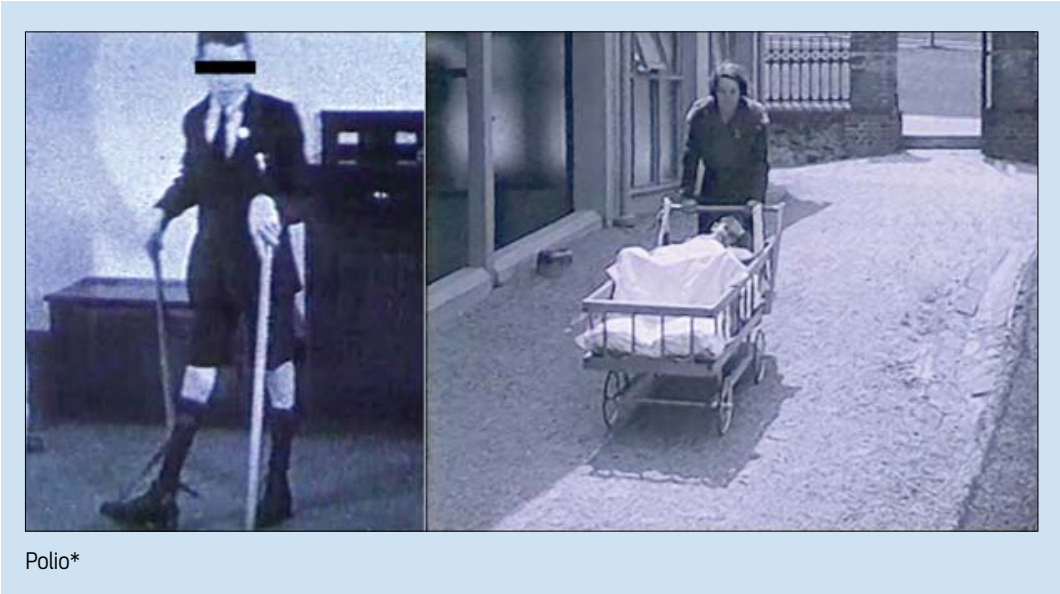


China in 2002-2003, is a bat virus ${ }^{38}$ but was transmitted to humans via infected palm civets, which were often for sale in Chinese markets. Control of SARS was achieved through international cooperation in identifying the new coronavirus and applying strict isolation procedures. ${ }^{39}$ Even so, the high mortality brought home to the world the potential threat of contagious disease. Memories of the 1918 influenza pandemic lent renewed vigour to the WHO surveillance system for respiratory infections that emerge from reservoirs of influenza viruses in pigs, horses, poultry and wild birds (the latter two in particular). Alas, the ability to identify novel strains has not been matched by the ability to predict infectivity and severity of disease.

Intensive agricultural production also provides new routes of infection. Mad cow disease resulted from the use of inadequately rendered animal-based food supplements for cattle which allowed the variant Creutzfeldt-Jakob disease agent to survive. ${ }^{40}$ Infected cattle often reached maturity and were slaughtered for human consumption before they developed clinical disease, and then humans became infected. The ramifications of this outbreak were economic and social. More new infections will undoubtedly emerge as humans change their environment. These pressures also affect old infections such as tuberculosis, malaria, cholera and even plague. The lessons of the past should not be forgotten.

\section{Looking ahead}

For a hundred years, the $M J A$ has reported on the overall decline of most infections in our "lucky country" — the result of our high standard of living combined with rational treatment and control measures. Aboriginal Australians who endure poverty and limited access to medical resources have not shared this luck. ${ }^{41}$ This mirrors the disparity in communicable diseases mortality between industrialised and developing countries. Abolishing this gap is the immediate priority for the forthcoming century.

\section{Competing interests: No relevant disclosures.}

Provenance: Commissioned; externally peer reviewed.

1 Ackerknecht EH. Anticontagionism between 1821 and 1867. Bull Hist Med 1948; 22: 562-593.

2 Taylor R, Lewis M, Powles J. The Australian mortality decline: all-cause mortality 1788-1990. Aust N Z J Public Health 1998; 22: 27-36.

3 Thompson JA. On the epidemiology of plague. J Hyg (Lond) 1906; 6: 537-569.

4 Hugh TB. The beginning of antiseptic surgery in Australia. Aust N Z J Surg 1995; 65: 887-889.

5 The diphtheria prophylactic of E. von Behring. Med J Aust 1914; 1: 160.

6 Lewis M, Bamber S, Waugh M, editors. Sex, disease and society: a comparative history of sexually transmitted diseases and HIV/AIDS in Asia and the Pacific. Westport: Greenwood Press, 1997.

7 Australian Quarantine Service. Maritime quarantine administration. Melbourne: Arthur J Mullett, Government Printer, 1919.

8 Trivett JB. Tuberculosis in New South Wales: a statistical analysis of the mortality from tubercular diseases during the last thirty-three years. Sydney: WA Gullick, Government Printer, 1909.

9 Ham BB. Consumption: report of a conference of principal medical officers on uniform measures for the control of consumption in the states of Australia. Melbourne: Government Printer, 1911.

10 Hillier AP. Tuberculosis: its nature, prevention, and treatment, with special reference to the open air treatment of phthisis. London: Cassell, 1900.

11 Williams HE, Phelan PD. The epidemiology, mortality and morbidity of tuberculosis in Australia: 1850-94. J Paediatr Child Health 1995; 31: 495-498.

12 Cumpston J. Health and disease in Australia: a history. Canberra: 1928.

13 Lancaster $\mathrm{HO}$. The mortality in Australia from measles, scarlatina and diphtheria. Med J Aust 1952; 2: 272-276.

14 Wilson $G$. The hazards of immunization. London: Athlone Press, 1967.

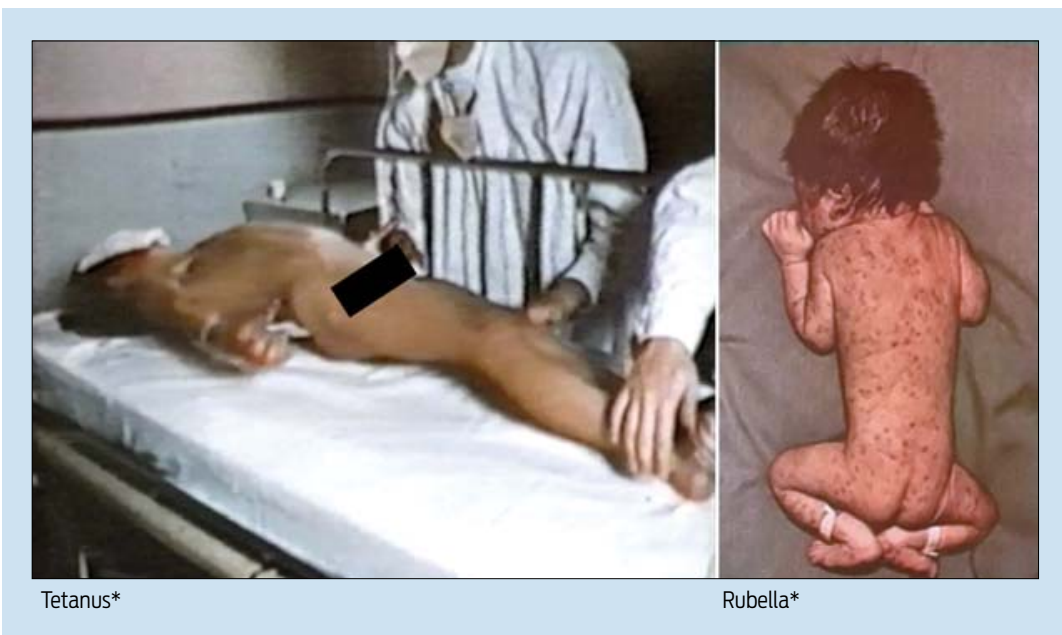

15 Butler AG. The Australian army medical services in the war of 1914-1918. Volume II. Canberra: Australian War Memorial, 1940.

16 Burnet FM. Natural history of infectious disease. 2nd ed. Cambridge: Cambridge University Press, 1953.

17 Gregg NM. Congenital cataract following German measles in the mother. Trans Ophthalmol Soc Aust 1941; 3: $35-46$.

18 Burgess M. Immunisation: a public health success. N S W Public Health Bull 2003; 14: 1-5.

19 Centers for Disease Control and Prevention. Progress toward global polio eradication - Africa, 2011. MMWR Morb Mortal Wkly Rep 2012; 61: 190-194.

20 Fenner F. A successful eradication campaign. Global eradication of smallpox. Rev Infect Dis 1982; 4: 916-930.

21 Katz AR, Morens DM. Severe streptococcal infections in historical perspective. Clin Infect Dis 1992; 14: 298-307.

22 Rountree PM. History of staphylococcal infection in Australia. Med J Aust 1978; 2: 543-546.

23 Cheng AC, Turnidge J, Collignon P, et al. Control of fluoroquinolone resistance through successful regulation, Australia. Emerg Infect Dis 2012; 18: 1453-1460.

24 Beeson PB. Jaundice occurring one to four months after transfusion of blood or plasma. Report of seven cases. JAMA 1943; 121: 1332-1334.

25 Szmuness W. Recent advances in the study of the epidemiology of hepatitis B. Am J Pathol 1975; 81: 629-650.

26 Stevens CE, Beasley RP, Tsui J, Lee WC. Vertical transmission of hepatitis B antigen in Taiwan. NEngl J Med 1975; 292: 771-774.

27 Beasley RP. Hepatitis B virus. The major etiology of hepatocellular carcinoma. Cancer 1988; 61: 1942-1956.

28 Tindall B, Cooper DA, Burcham J, et al. Clinical and immunologic sequelae of AIDS retrovirus infection. Aust NZ J Med 1986; 16: 749-756.

29 Butler D. AIDS. In and out of Africa. Nature 2000; 408: 901-902.

30 Crofts N, Jolley D, Kaldor J, et al. Epidemiology of hepatitis C virus infection among injecting drug users in Australia. J Epidemiol Community Health 1997; 51: 692-697.

31 Levy MT, Chen JJ, McGuinness PH, et al. Liver transplantation for hepatitis C-associated cirrhosis in a single Australian centre: referral patterns and transplant outcomes. J Gastroenterol Hepatol 1997; 12: 453-459.

32 zur Hausen H. Papillomaviruses and cancer: from basic studies to clinical application. Nat Rev Cancer 2002; 2: $342-350$.

33 Frazer IH. HPV immunisation: a significant advance in cancer control. Gynecol Oncol 2007; 107 (2 Suppl 1): S1.

34 Murray CJ, Rosenfeld LC, Lim SS, et al. Global malaria mortality between 1980 and 2010: a systematic analysis. Lancet 2012; 379: 413-431.

35 Barzilay EJ, Schaad N, Magloire R, et al. Cholera surveillance during the Haiti epidemic - the first 2 years. NEngl J Med 2013; 368: 599-609.

36 Lee HW. Hemorrhagic fever with renal syndrome in Korea. Rev Infect Dis 1989; 11 Suppl 4: S864-S876.

37 McCormack JG, Allworth AM. Emerging viral infections in Australia. Med J Aust 2002; 177: 45-49.

$38 \mathrm{Li}$ W, Shi Z, Yu M, et al. Bats are natural reservoirs of SARS-like coronaviruses. Science 2005; 310: 676-679.

39 World Health Organization Multicentre Collaborative Network for Severe Acute Respiratory Syndrome Diagnosis. A multicentre collaboration to investigate the cause of severe acute respiratory syndrome. Lancet 2003; 361: 1730-1733.

40 Tyrrell DA. An overview of bovine spongiform encephalopathy (BSE) in Britain. Dev Biol Stand 1992; 76: 275-284.

41 Bramley D, Hebert P, Jackson R, Chassin M. Indigenous disparities in disease-specific mortality, a cross country comparison: New Zealand, Australia, Canada, and the United States. N Z Med J 2004; 117: U1215.

* The images published with this article were taken from a public education video titled "Protect your baby for life", which briefly profiled particular infectious diseases so parents were better informed about vaccinating their children. The video was made possible by Professor Clem Boughton and his colleagues from the Department of Infectious Diseases, Prince Henry Hospital and Prince of Wales Hospital, and the University of New South Wales. The images were prepared by the Sydney School of Medicine, University of Notre Dame Australia. 